\title{
The rise and fall of photosynthesis: hormetic dose response in plants
}

\author{
Evgenios Agathokleous ${ }^{1}$
}

Received: 13 September 2020 / Accepted: 3 October 2020 / Published online: 17 November 2020

(C) The Author(s) 2020

\begin{abstract}
The recent recognition that low doses of herbicides, human and veterinary antibiotics, metallic elements, micro/nano-plastics, and various other types of environmental pollutants widely enhance chlorophylls in the framework of hormesis created the need to further evaluate the response of photosynthetic pigments and gas exchange to low doses of stresses. An analysis of about 370 values of maximum stimulatory response (MAX; percentage of control response, $\%$ ) of chlorophylls in higher plants, algae and duckweeds, and other photosynthesizing organisms, mined from published literatures, revealed a greater MAX for higher plants (median $=139.2 \%)$ compared to algae and duckweeds $($ median $=119.6 \%)$. However, an analysis of about 50
\end{abstract}

Four original papers traced after this paper was accepted for publication report data suppoting the views presented herein (Adamakis et al.2020; de Alkimin et al. 2020; dos Santos et al. 2020; Sharma et al. 2020).

Project funding: This work was supported by the Startup Foundation for Introducing Talent of Nanjing University of Information Science \& Technology (NUIST), Nanjing, China (Grant No. 003080).

The online version is available at http://www.springerlink.com.

Corresponding editor: Yu Lei.

Electronic supplementary material The online version of this article (https://doi.org/10.1007/s11676-020-01252-1) contains supplementary material, which is available to authorized users.

Evgenios Agathokleous evgenios@nuist.edu.cn

1 Key Laboratory of Agrometeorology of Jiangsu Province, Institute of Applied Ecology, Nanjing University of Information Science and Technology (NUIST), Nanjing, China mined values of MAX of carotenoids revealed no significant difference in the median MAX between higher plants $($ median $=133.0 \%)$ and algae-duckweeds $($ median $=138.1 \%)$. About 70 mined values of MAX were also concentrated for photosynthetic rate (median MAX $=129.2 \%$ ) and stomatal conductance (median MAX $=124.7 \%$ ) in higher plants. Within higher plants, there was no significant difference in the median MAX among chlorophylls, carotenoids, photosynthetic rate, and stomatal conductance. Similarly, there was no significant difference in the median MAX between chlorophylls and carotenoids of pooled algae and duckweeds. The results suggest that the MAX is typically below $160 \%$ and as a rule below $200 \%$ of control response, and does not differ among chlorophylls, carotenoids, photosynthetic rate, and stomatal conductance. New research programs with improved experimental designs, in terms of number and spacing of doses within the "low-dose zone" of the hormetic dose-response relationship, are needed to study the molecular/genetic mechanisms underpinning the low-dose stimulation of photosynthesis and its ecological implications.

Keywords Dose-response relationship · Environmental stresses $\cdot$ Hormesis $\cdot$ Photosynthesis $\cdot$ Low-dose stimulation

\section{Introduction}

Photosynthesis converts sunlight into energy, thus driving plant growth and productivity, and contributes in sustaining life on the planet as it uses water to release oxygen in the atmosphere. Because improving photosynthesis can also contribute to ensuring food security, photosynthesis has been a key target of bioengineering manipulations for a long time (Evans 2013; South et al. 2019; Simkin et al. 2019; Sinclair 
et al. 2019). Such manipulations aiming at improving photosynthesis have targeted various physiological functions, such as photorespiration, ribulose-1,5-bisphosphate carboxylase/ oxygenase (Rubisco), the Calvin-Benson cycle, and electron transport (Evans 2013; South et al. 2019; Simkin et al. 2019). However, a vast literature demonstrates that various abiotic stresses (including environmental pollutants) cause over-reduction of the electron transport chain and photooxidation, and extensively discusses the underpinning mechanisms of these adverse effects on photosynthesis (Heath 1994; Gururani et al. 2015; Li et al. 2017).

To understand how photosynthesis responds to environmental stresses, predict the effects of specific levels of pollutants, and derive critical levels of pollutants above which photosynthesis is adversely affected, dose-response relationships should be studied. Hormesis is a dose ${ }^{1}$-response phenomenon where low doses of stress stimulate and high doses of stress adversely affect plants, producing biphasic dose-response relationships (Cedergreen et al. 2007; Belz 2008; Calabrese and Blain 2009). This dose-response relationship indicates that (1) biologically significant effects can occur at stress doses multi-fold smaller than the dose where the traditional toxicological threshold appears (i.e. noobserved-adverse-effect-level, NOAEL), and (2) prediction of effects by extrapolating from considerably higher doses to lower doses based on a linear-no-threshold perspective can generate incorrect estimates of inhibition at doses where even stimulation might occur (Calabrese and Blain 2009; Agathokleous et al. 2020c). However, there is no integrated documentation of hormetic response of photosynthesis to various environmental stresses.

The recent years have witnessed the widespread occurrence of hormesis in numerous plant species exposed to an array of environmental stresses, including contemporary emerging contaminants (Calabrese and Blain 2009; Hadacek et al. 2010; Erofeeva 2014; Morkunas et al. 2018; Agathokleous et al. 2020c; Macias-Bobadilla et al. 2020). Well-documented stresses inducing hormesis in plants are active pharmaceuticals (Agathokleous et al. 2018), air pollutants (Agathokleous et al. 2019a; Erofeeva and Yakimov 2020; Erofeeva 2020), hydrocarbons (Agathokleous et al. 2020a), metals, toxic ions and trace elements (Poschenrieder et al. 2013; Carvalho et al. 2020; Shahid et al. 2020), nanomaterials (Iavicoli et al. 2014; Agathokleous et al. 2019b), and pesticides and other agrochemicals (Garzon and Flores 2013; Brito et al. 2018; Agathokleous et al. 2019c, d; Jalal et al. 2021). These studies indicated that hormesis is a widely occurring phenomenon in plants exposed to single or combined stresses, with generalized quantitative characteristics; the maximum low-dose stimulation is modest, and as

\footnotetext{
${ }^{1}$ Dose refers to both concentration and dose hereafter.
}

a rule less than two-fold the control response (Agathokleous et al. 2020c).

As the basis of photosynthesis is chlorophyll whose response to increasing doses of stress has been widely found to be biphasic (i.e. typical of hormesis), and because photosynthesis is regulated by other functions displaying biphasic dose responses (Poschenrieder et al. 2013; Agathokleous et al. 2019e, 2020b; Jalal et al. 2021), photosynthetic rate may also show biphasic dose-response relationships (Cedergreen and Olesen 2010; Jia et al. 2015; Deng et al. 2017; Di Baccio et al. 2017; Wu et al. 2018; Hussain et al. 2019; Gohari et al. 2020a, b). To this end, this study aimed at collating evidence documenting biphasic dose-responses of photosynthetic rate and stomatal conductance to various stresses (Fig. 1), and examining whether the maximum stimulatory response (MAX) to low doses of environmental stresses differs among groups of photosynthesizing organisms, among photosynthetic pigments (chlorophylls and carotenoids) and gas exchange (photosynthetic rate and stomatal conductance) traits.

\section{Analysis}

\section{Chlorophylls in higher plants}

The methodology of data extraction, response calculation, and data analysis used in this section was same as described previously (Agathokleous et al. 2020b). Briefly, MAX was considered the greatest stimulation (\% of control response) induced by stress in each dose-response evaluation. The raw data were extracted (with six decimals) from the original articles using Adobe Photoshop CS4 Extended v.11 (Adobe Systems Incorporated, CA, USA), and the maximum stimulatory responses were calculated as the percent difference from the response of control group.

To assess whether the dose-response samples of 2 or more groups were from different distributions, the dose-response data were subjected to Kruskal-Wallis tests by ranks (Figs. 2-5); the level of significance was predefined at $\alpha=0.05$. The level of $\alpha$ was corrected against inflation of the rate of false positive with a Bonferroni correction for significant Kruskal-Wallis tests with independent variables including 3 or more groups, with at least a sample stochastically dominating another sample. Data were processed and analyzed using EXCEL 2010 and STATISTICA v.10 (StatSoft Inc.).

A study conducted in late 2019 identified 177 dose responses of chlorophylls to over 20 stress-inducing agents, in 33 higher plant species and 43 experimental setups (Agathokleous et al. 2020b). In the framework of this paper, the earlier database (Agathokleous et al. 2020b) was extended by adding 121 dose responses of chlorophylls to 

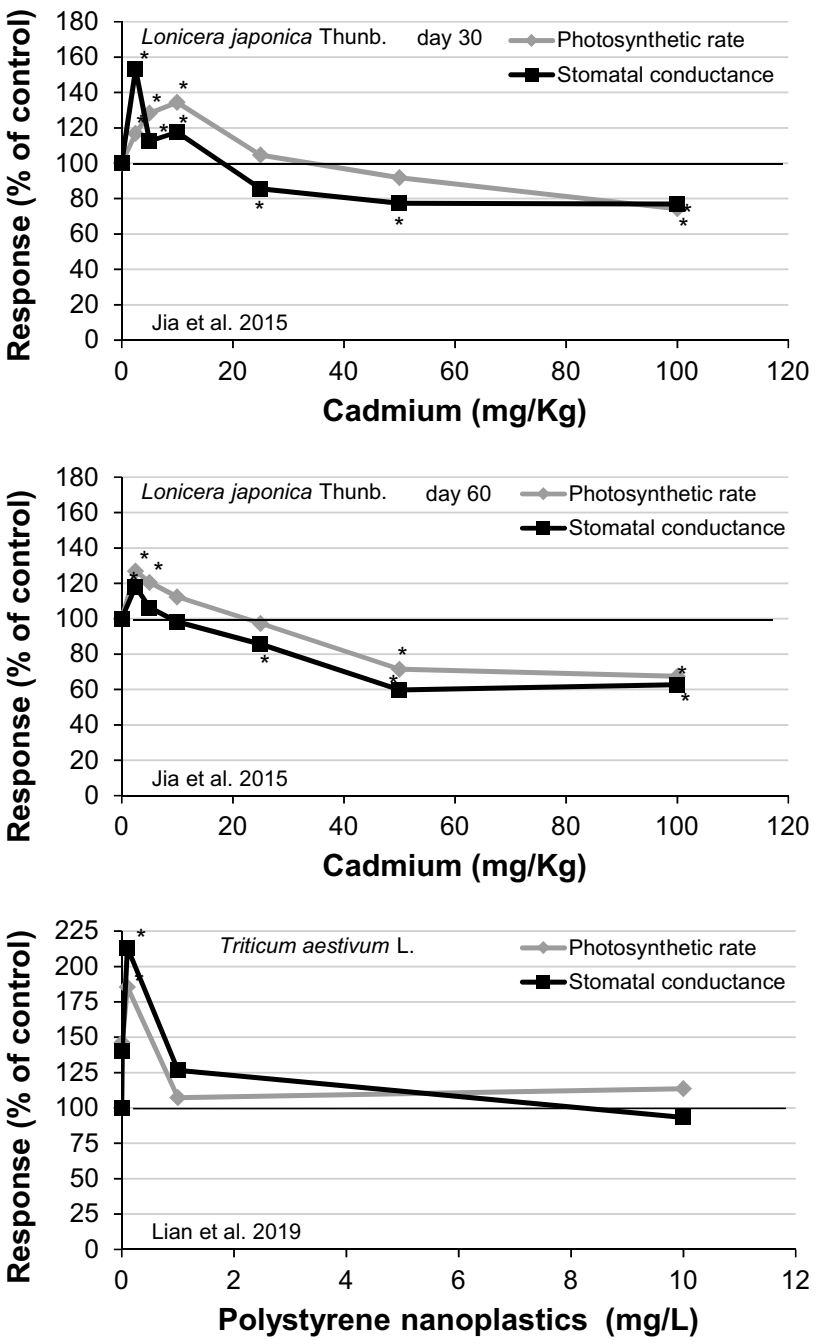

Fig. 1 Examples of biphasic dose-response relationships, typical of hormesis in plants. Asterisk above or below a mean response indicates statistical significance compared to the control group, according to the statistical analyses in the original paper. The raw data were extracted from the original articles using Adobe Photoshop CS4 Extended v.11 (Adobe Systems Incorporated, CA, USA)

22 stresses, mined from 25 published studies (of which $67 \%$ were published in 2020) with 24 species of higher plants, including tree and other perennial plants (Table S1). The 22 stresses included herbicides (Liu et al. 2019; Meseldžija et al. 2020), human and veterinary antibiotics (Guo et al. 2020; Liu et al. 2020a), metallic elements (Seth et al. 2008; Tang et al. 2009; Jia et al. 2015; Apodaca et al. 2017; Wu et al. 2018; Li et al. 2020a; Małkowski et al. 2020; Mo et al. 2020; Yang et al. 2020), micro/nano-plastics (Dong et al. 2020; Li et al. 2020c; Lian et al. 2020; Pignattelli et al. 2020), and various other types (Mostofa et al. 2015; Wang et al. 2016; Soliman et al. 2019; Kutty et al. 2020; He et al. 2020; Gohari et al. 2020b, a; Trejo-Téllez et al.

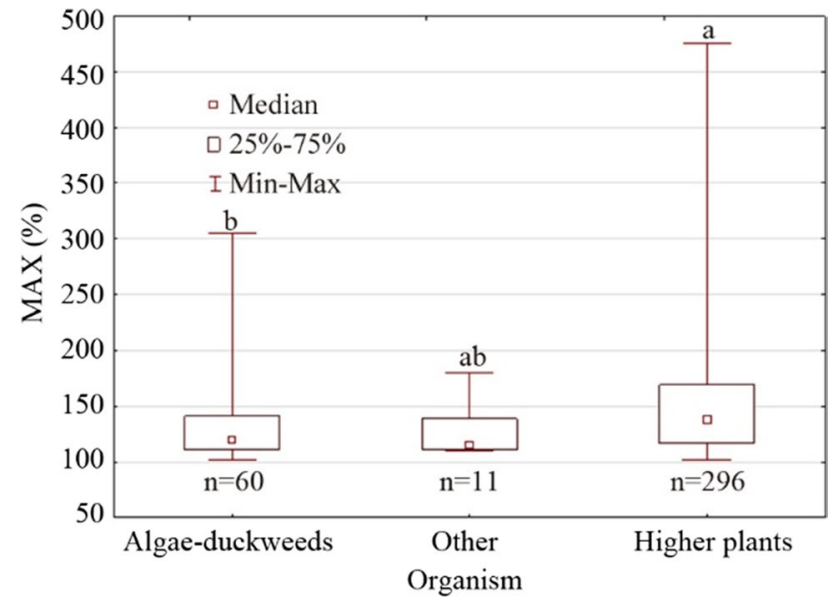

Fig. 2 The maximum stimulatory response (MAX, \% of control response) of chlorophylls for different groups of organisms. Different letters above the min-max bars indicate samples of organism groups were from different distributions, after Kruskal-Wallis tests by ranks. The alpha level was pre-set at a value of 0.05 . Note: Kruskal-Wallis tests by ranks was significant $(H=14.17, P<0.001)$. As explained before (Agathokleous et al. 2020b), two entries of the old database of higher plants were extreme, and not in accordance with hormesis understandings (e.g. 5938.7\% and 1235.5\%). Therefore, the analysis was repeated after excluding these two values to test how they might have affected the results (this figure does not include the two extreme values for presentation purposes). The result $(H=13.68, P<0.01)$ was similar with the first analysis (and multiple comparisons same), suggesting that the two extreme values did not affect the analysis

2020). More than half (57.0\%) of the new dose responses were statistically significant compared with the control group (typically a zero dose of the same stressor), according to the original analysis (many of them did not report statistics). Kruskal-Wallis Test was not significant $(H=0.11$, $P=0.738$ ) between the old and the new databases (Fig. S1), and the databases were merged for analysis. The median MAX was $139.2 \%$ (geometric mean $=150.7 \%$ ), and as many as $68.8 \%$ and $83.9 \%$ of the 298 entries had a MAX smaller than $160 \%$ and $200 \%$ of the control response, respectively, estimates that are in agreement with the broad plant hormesis literature (Calabrese et al. 2019; Agathokleous et al. 2020c; Shahid et al. 2020).

\section{Chlorophylls in organisms other than higher plants}

Making one step further, 20 studies with photosynthetic organisms other than higher plants were found to report dose-response data potentially suggestive of hormesis. An assessment of these studies revealed 71 dose responses (Table S2) of chlorophylls to herbicides (Wong and Chang 1988; Rioboo et al. 2002; Zaltauskaite and Kaciene 2020), human and veterinary antibiotics (Hu et al. 2019; Jiang et al. 2020; Tong et al. 2020), metallic elements (Zhou et al. 2018; 
Li et al. 2020b), micro/nano-plastics (Tang et al. 2018; Chae et al. 2019; Zhao et al. 2019; Su et al. 2020; Song et al. 2020; Zhang et al. 2020), and other types of stresses (Zhou et al. 2016; Deng et al. 2017; Zhang et al. 2018, 2020; Cai et al. 2020; Liu et al. 2020b; Xue et al. 2020). These dose responses come from 16 species (one non-identified), and $31 \%$ were statistically significant compared with the control group, according to the original analysis (some papers did not report statistics). The median MAX was $120.5 \%$ (geometric mean $=137.4 \%$ ), while $85.9 \%$ and $90.1 \%$ of the 71 entries had a MAX smaller than $160 \%$ and $200 \%$ of the control response, respectively. These suggest that the MAX is restricted below $200 \%$ of control response, in agreement with the chlorophyll response of higher plants as well as the broad hormesis literature (Calabrese et al. 2019; Agathokleous et al. 2020c; Shahid et al. 2020).

\section{Comparing chlorophylls MAX among groups of photosynthesizing organisms}

In order to understand whether chlorophyll MAX differs among groups of organisms, a further analysis was carried out. Three groups were created: (1) higher plants, (2) (micro) algae and duckweed, and (3) other organisms (cyanobacteria, dinoflagellates, and symbiotic zooxanthellae, i.e. scleractinian corals). This analysis revealed that samples of groups 1 and 2 were from different distributions (Fig. 2), which is in agreement with an analysis of nanomaterial-induced MAX, according to which the median MAX was $119.7 \%(n=46)$ and significantly lower in algae than in plants $(125.2 \%$, $n=453$ ) across all traits and plant species (Agathokleous et al. 2019b). While these may arise from differences in the stress biology between vascular plants and algae (Pinnola and Griffiths 2019) or a potentially more efficient light utilization and gas exchange in terrestrial systems compared to aquatic systems (Sand-Jensen 1997), the sample size of algae/duckweeds was considerably small in both analyses, not permitting any concrete conclusions at this stage. However, these findings indicate a need for more studies in order to better understand the biological responses of vascular and non-vascular plants to low doses of environmental stresses.

\section{Carotenoids in higher plants and algae/duckweeds.}

Carotenoids are the second most abundant pigments occurring naturally. They also serve as precursors of certain volatiles, abscisic acid, various apocarotenoids, and strigolactone, and play important roles as accessory light-harvesting photosynthetic pigments, antioxidants, and attractants for pollinators and seed dispersers (Havaux 2014; Nisar et al. 2015; Alós et al. 2016). Hence, not only chlorophylls (Agathokleous et al. 2020b) but also carotenoids have a multitude of roles in plant-plant competition, plant interaction

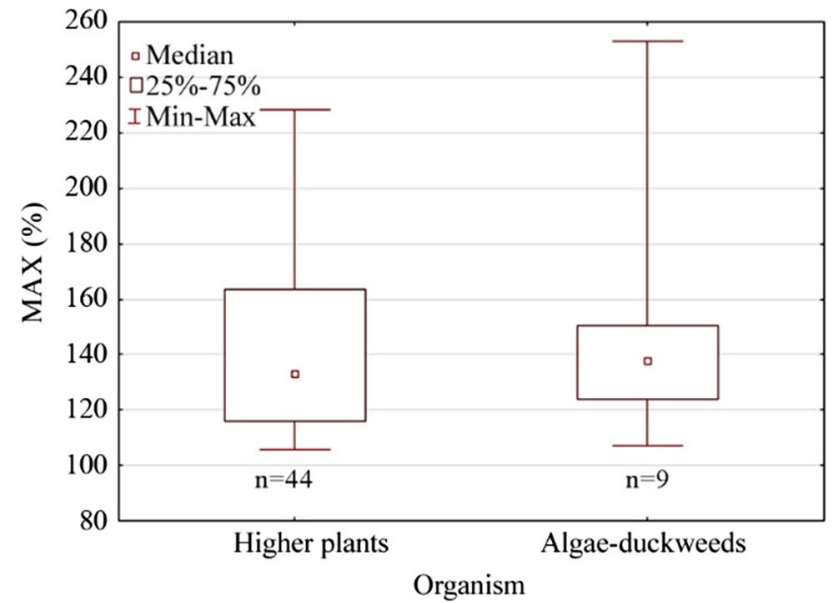

Fig. 3 The maximum stimulatory response (MAX, \% of control response) of carotenoids for different groups of organisms. Carotenoids are involved in the light-harvesting complex during photosynthesis as well as the protection against photo-oxidation. Kruskal-Wallis test by ranks was non-significant $(H=0.20, P=0.653)$

with other organisms (e.g. insects), and plants success in the environment. Therefore, potential enhancement of carotenoids by low doses of pollutants might have unpredicted ecological consequences. For these reasons, carotenoids are an important trait for studying the effects of low doses of pollutants.

In a number of studies reporting responses of leaf photosynthetic pigments to stresses, data of carotenoids response were also included ( $n=16$ studies with higher plants and $n=5$ studies with algae and duckweeds). These data were collected and further analyzed; $45.5 \%$ of the mined dose responses with higher plants and $44.4 \%$ of the mined dose responses with algae and duckweeds were statistically significant according to the original analyses of authors (Supplementary Information, Tables S3-S4). The median MAX was $133.0 \%$ for higher plants (geometric mean $=140.8 \%$ ) and $138.1 \%$ for algae and duckweeds (geometric mean $=145.2 \%$ ) exposed to human and veterinary antibiotics (Liu et al. 2020a), herbicides (Rioboo et al. 2002; Liu et al. 2019; Zaltauskaite and Kaciene 2020), metallic elements (Jia et al. 2015; Zhou et al. 2018; Wu et al. 2018; Hussain et al. 2019; Liu et al. 2019), micro/nano-plastics (Li et al., 2020c, d; Pignattelli et al. 2020; Song et al. 2020), and other stressinducing agents (Mostofa et al. 2015; Farzana and Tam 2018; Dawood and Azooz 2019; Lassalle et al. 2019; Li et al. 2019; Soliman et al. 2019; Tombuloglu et al. 2019; Gohari et al. 2020b, a). The median MAX did not differ significantly between the two groups of organisms, although the sample size was small (Fig. 3). 


\section{Photosynthetic rate and stomatal conductance in higher plants.}

Sixteen studies with data suggestive of biphasic responses of higher plants photosynthesis were traced. These included responses to herbicides (Cedergreen and Olesen 2010; de Carvalho et al. 2012; Adams et al. 2017; Nascentes et al. 2018; Khan et al. 2020), metallic elements (Jia et al. 2015; Chandra and Kang 2016; Wu et al. 2018; Gelioli Salgado et al. 2019; Małkowski et al. 2020; Mendonça et al. 2019; Yang et al. 2020), micro/nano-plastics (Dong et al. 2020; Lian et al. 2020), and other types of stresses (Sugai et al. 2018; Soliman et al. 2019). Low-dose stimulation of photosynthetic rate by various stresses appeared in various taxa of trees, shrubs, and vines (de Carvalho et al. 2012; Jia et al. 2015; Chandra and Kang 2016; Adams et al. 2017; Nascentes et al. 2018; Mendonça et al. 2019; Yang et al. 2020). Furthermore, biphasic dose-responses of photosynthetic rate to stresses were observed not only in $\mathrm{C} 3$ plants but also in C4 plants (Zea mays L.) (Małkowski et al. 2020). While some studies report data suggestive of hormetic responses of algae and duckweeds to stresses, in terms of biphasic responses of photosynthesis (Wong and Chang 1988; Di Baccio et al. 2017), their number is small and, thus, only the dose responses of higher plants were further analyzed. From the 16 traced studies with higher plants, 65 dose responses were mined, of which 38 concerned photosynthetic rate and 27 concerned stomatal conductance (Supplementary Information, Table S5). From the mined dose responses, 64.6\% were statistically significant compared to the control group (as a rule a theoretically zero exposure), according to the original statistics (Table S5). The median MAX was 129.2\% for photosynthesis (geometric mean $=134.1 \%$ ) and $124.7 \%$ for stomatal conductance (geometric mean $=133.4 \%$ ).

\section{Comparing MAX among physiological traits}

The present results raised the curiosity of this author to further evaluate whether MAX differs among physiological traits. To this end, an analysis of the MAX among chlorophyll content/concentration, carotenoid content/concentration, photosynthetic rate, and stomatal conductance in higher plants was carried out. According to the statistical results, the four traits shared a similar median MAX (Fig. 4). A similar analysis was also conducted for the MAX of chlorophyll content/concentration and carotenoid content/concentration of algae and duckweeds. This analysis also suggests that the median MAX was similar between chlorophylls and carotenoids (Fig. 5).

Different groups of organisms were subjected to different types of stresses, so comparison of MAX might be influenced in cases where the sample size (number of dose

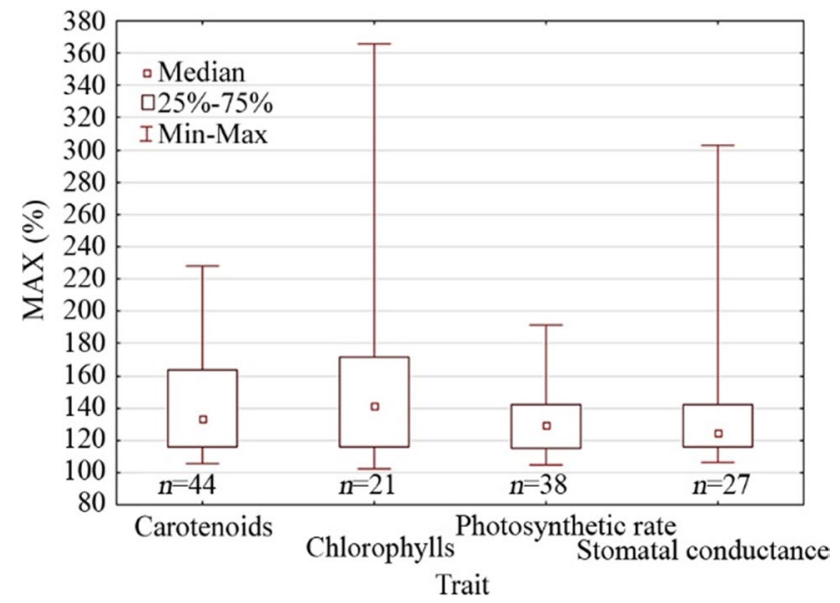

Fig. 4 The maximum stimulatory response (MAX, \% of control response) of higher plants per physiological trait. Kruskal-Wallis test by ranks was non-significant $(H=5.23, P=0.156)$

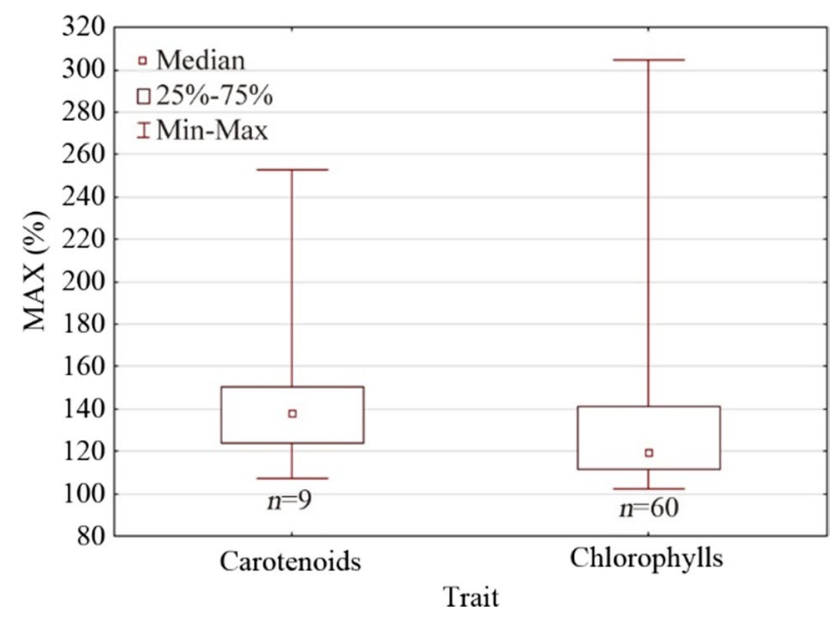

Fig. 5 The maximum stimulatory response (MAX, \% of control response) of algae and duckweeds per physiological trait. KruskalWallis test by ranks was non-significant $(H=2.60, P=0.107)$

responses) is small, such as for carotenoids in algae and duckweeds (Fig. 5). This shortcoming suggests that such results should be interpreted with caution. However, extensive databases including $>10000$ dose responses suggest that the median MAX does not differ significantly, or the difference (if any) is negligible, among types of pollutants (Calabrese and Blain 2009; Agathokleous et al. 2018, 2019a,b,c,d; Agathokleous et al. 2020a, b,c; Shahid et al. 2020). This phenomenon holds true for specific traits as well, i.e. chlorophylls (Agathokleous et al. 2020b), permitting the analyses of MAXs across different groups of organisms or photosynthesis-related traits with response data pooled together across stresses. 


\section{Discussion}

Studies with multifactorial experimental designs including different levels of co-occurring stresses suggest that lowdose stimulation of photosynthetic pigments and photosynthesis is more likely to occur under "disease conditions" in the framework of conditioning hormesis, i.e. when plants are under adverse stress induced by other factors, but the stimulation also ceases as the dose of the concurrent stresses exceeds a specific threshold of adversity (Mostofa et al. 2015; Gelioli Salgado et al. 2019; Liu et al. 2019; Soliman et al. 2019; Agathokleous et al. 2020b; Dong et al. 2020; Gohari et al. 2020b; Gohari et al. 2020a; Li et al. 2020c; Yang et al. 2020;). These suggest that the magnitude of the low-dose stimulation by an environmental stressor significantly depends on the intensity of co-occurring environmental stresses.

The low-dose enhancement of chlorophylls and gas exchange (Seth et al. 2008; de Carvalho et al. 2012; Tang et al. 2018; Zhou et al. 2018; Zhao et al. 2019; Hu et al. 2019; Liu et al. 2020a) in higher plants and other photosynthetic organisms may be transient. However, this may indicate that the doses applied may become higher or smaller than those needed to induce MAX (as they accumulate or decline over time) because considerable research designed to study hormesis shows that the low-dose stimulation of chlorophylls and photosynthesis can persist throughout the plant growing season (Jia et al. 2015; Nascentes et al. 2018; Yang et al. 2020), yet it is known that the maximum stimulation occurs over a defined time window, after which it declines (Agathokleous et al. 2020b, c). Ceasing of the exposure is also expected to lead to returning to the control/background levels of chlorophylls to allow for recovery and maintenance of a homeostatic state (Zaltauskaite and Kaciene 2020). These suggest that research programs designed to study hormetic interventions directed to enhance plant photosynthesis should consider the temporal component to identify optimum intervention intervals.

The modest and generalized degree of MAX, typically $130-160 \%$ (as a rule $<200 \%$ ) of control response, indicates that the low-dose stimulation is restricted by the limits of biological plasticity (Calabrese and Blain 2009; Calabrese et al. 2019; Agathokleous et al. 2020c; Shahid et al. 2020). Interestingly, the degree of enhancement of photosynthesis (e.g. $\approx 130 \%-150 \%$ ) and other traits by elevated concentrations of atmospheric $\mathrm{CO}_{2}$ (Fajer and Bazzaz 1992; Kirschbaum 2011) presents an excellent agreement with the degree of enhancement by various environmental pollutants as analyzed here for photosynthetic pigments and photosynthesis as well as across traits and species (Calabrese and Blain 2009; Calabrese et al. 2019; Agathokleous et al. 2020c; Shahid et al. 2020). The enhancement of plants by $\mathrm{CO}_{2}$ may be seen as a fertilizing effect of $\mathrm{CO}_{2}$ where the rate of photosynthesis increases with increasing concentrations of $\mathrm{CO}_{2}$ in the atmosphere (so called carbon fertilization), while the enhancement of plants by other environmental stresses causing oxidative stress (discussed in Sect. 2) appears to occur in the framework of an ecological strategy of plants to prepare for forthcoming 'life-threatening' stress. The underlining molecular mechanisms of hormesis induced in plants by environmental pollutants remain poorly understood, but it may be hypothesized that plants may increase their photosynthetic rate so to increase carbon availability and potentially enhance the carbon-based defense system, including enhanced secondary metabolites as well as other defensive molecules. However, while some evidence of these speculations exists (explained later in the text), further studies are needed to examine these from the perspective of hormesis.

An inverted U-shaped dose-response relationship of chlorophylls and photosynthesis response to stresses was found to be consistent with biomass response pattern of higher terrestrial plants (Tang et al. 2009; Jia et al. 2015; Nascentes et al. 2018; Li et al. 2019; Lassalle et al. 2019; Gohari et al. 2020b; Khan et al. 2020; Lian et al. 2020) and aquatic duckweed (Zaltauskaite and Kaciene 2020) microalgae (Zhou et al. 2016). However, it should be highlighted that increased photosynthetic rate may not necessarily translate to increased photosynthetic efficiency or growth; e.g. a $30 \%$ average enhancement of photosynthesis over the course of the day under elevated $\mathrm{CO}_{2}$ may increase relative growth rate by only $\approx 10 \%$ (Kirschbaum 2011).

The underlying mechanisms of the stimulation of photosynthesis by environmental pollutants in the framework of hormesis remain underexplored (de Carvalho et al. 2012). The stimulation of chlorophylls by low-dose stress was found to co-occur with inhibition of chlorophyllase and $\mathrm{Mg}$-dechelatase (Yang et al. 2020). Hormetic-like (inverted U-shaped) dose-response relationship was also found for defensive compounds such as $\alpha$-tocopherol, ascorbic acid, phenolic compounds, flavonoids, and phytochelatins; it was similar to chlorophylls dose-response relationship (Dawood and Azooz 2019; Gohari et al. 2020b). Nitric oxide appeared to have a similar dose response (Dawood and Azooz 2019). Other molecules related to anti-oxidant properties with similar hormetic-like responses were reduced glutathione, superoxide dismutase, catalase, ascorbate peroxidase, and glutathione peroxidase (Dawood and Azooz 2019; Gohari et al. 2020b, a). It is noteworthy that hormetic-like (inverted U-shaped) dose-response relationship similar to chlorophylls was also found for xanthophylls ( $\mathrm{Hu}$ et al. 2019). A major knowledge gap, however, exists with regard to the production and fate of unproductive by-products (Simkin et al. 2019) of increased photosynthesis due to low doses of environmental pollutants.

An increase in the rates of carbon fixation and/or their efficiency can result from increasing light harvesting and/ 
or stomatal and mesophyll conductance (de Carvalho et al. 2012). Coupled stimulation of photosynthesis and stomatal conductance under low-dose stress and coupled inverted U-shaped dose-response relationships were revealed (de Carvalho et al. 2012; Jia et al. 2015; Nascentes et al. 2018; Mendonça et al. 2019; Soliman et al. 2019; Lian et al. 2020; Małkowski et al. 2020; Yang et al. 2020). In some other cases, however, the stimulation of photosynthesis and stomatal conductance was uncoupled as to the magnitude and inducing dose, with shifts in the dose-response relationship (Nascentes et al. 2018; Wu et al. 2018; Małkowski et al. 2020). These suggest that the increase in photosynthesis due to low doses of environmental pollutants is not exclusively or primarily driven by increased stomatal conductance, a phenomenon indicating that other biochemical mechanisms (e.g. Rubisco, Ribulose 1,5-bisphosphate, triose phosphate utilization) may primarily drive the low-dose stimulation of photosynthesis. Within the low-dose zone, photosynthesis response was also found to correlate with respiration response (Cedergreen and Olesen 2010) (Fig. S2). It was also observed that in several of the examined cases of gas exchange response to stresses transpiration was also enhanced by low doses, a phenomenon that may indicate increased nutrient absorption efficiency with a potential for greater nutrient supply to aboveground tissues.

\section{Conclusion}

The herein analysis represents the first integrated documentation of plant hormesis as reflected to biphasic dose-response of gas exchange to various stresses. Preliminary but significant evidence suggests the widespread stimulation of photosynthesis by low doses of environmental pollutants. However, stimulation of photosynthesis by low doses of stress is also known to occur in response to nonessential elements that are not environmental pollutants, such as silicon that may also induce U-shaped dose-response relationships (Cooke and Leishman 2016; Li et al. 2018; Xu et al. 2020), signifying the importance of low-dose effects on photosynthesis.

While this may be seen as a preliminary analysis, it substantiates that enhanced awareness of researchers about these hormetic responses of plants would help in identifying such responses and facilitating cumulative science for a more complete and enhanced understanding of low-dose effects on plant photosynthesis, as well as improved toxicological estimates and risk assessment.

New studies directed to study hormetic responses of plants to environmental pollutants should consider to identify a 'true' MAX by studying dose-response relationships incorporating increased number of doses ( $>6$ doses), with narrower spacing, below the NOAEL (Calabrese et al. 2019).
Open Access This article is licensed under a Creative Commons Attribution 4.0 International License, which permits use, sharing, adaptation, distribution and reproduction in any medium or format, as long as you give appropriate credit to the original author(s) and the source, provide a link to the Creative Commons licence, and indicate if changes were made. The images or other third party material in this article are included in the article's Creative Commons licence, unless indicated otherwise in a credit line to the material. If material is not included in the article's Creative Commons licence and your intended use is not permitted by statutory regulation or exceeds the permitted use, you will need to obtain permission directly from the copyright holder. To view a copy of this licence, visit http://creativecommons.org/licenses/by/4.0/.

\section{References}

Adamakis I-DS, Sperdouli I, Hanć A, Dobrikova A, Apostolova E, Moustakas M (2020) Rapid hormetic responses of photosystem II photochemistry to cadmium exposure. Preprints 2020110283. https://doi.org/10.20944/preprints202011.0283.v1

Adams JP, Pelkki MH, Ford VL et al (2017) Initial effects of quinclorac on the survival and growth of high biomass tree species. Ann For Res 60:75-87. https://doi.org/10.15287/afr.2016.734

Agathokleous E, Araminiene V, Belz RG et al (2019) A quantitative assessment of hormetic responses of plants to ozone. Environ Res 176:108527. https://doi.org/10.1016/j.envres.2019.108527

Agathokleous E, Barceló D, Tsatsakis A, Calabrese EJ (2020) Hydrocarbon-induced hormesis: 101 years of evidence at the margin? Environ Pollut 265:114846. https://doi.org/10.1016/j. envpol.2020.114846

Agathokleous E, Feng Z, Iavicoli I, Calabrese EJ (2019) The two faces of nanomaterials: A quantification of hormesis in algae and plants. Environ Int 131:105044. https://doi.org/10.1016/j. envint.2019.105044

Agathokleous E, Feng ZZ, Calabrese EJ (2019) The systemic herbicide 2,4-Dichlorophenoxyacetic acid (2,4-D) is another hormetin: What does it mean for agriculture and the environment? J Agric Food Chem 67:9695-9696. https://doi.org/10.1021/ acs.jafc. 9 b04757

Agathokleous E, Feng ZZ, Peñuelas J (2020) Chlorophyll hormesis: Are chlorophylls major components of stress biology in higher plants? Sci Total Environ 726:138637. https://doi. org/10.1016/j.scitotenv.2020.138637

Agathokleous E, Kitao M, Calabrese EJ (2020) Hormesis: Highly generalizable and beyond laboratory. Trends Plant Sci 25:1076-1086. https://doi.org/10.1016/j.tplants.2020.05.006

Agathokleous E, Kitao M, Calabrese EJ (2018) Human and veterinary antibiotics induce hormesis in plants: Scientific and regulatory issues and an environmental perspective. Environ Int 120:489-495. https://doi.org/10.1016/j.envint.2018.08.035

Agathokleous E, Kitao M, Calabrese EJ (2019) Hormetic dose responses induced by lanthanum in plants. Environ Pollut 244:332-341. https://doi.org/10.1016/j.envpol.2018.10.007

Agathokleous E, Kitao M, Harayama H (2019) On the non-monotonic, hormetic photoprotective response of plants to stress. Dose-Response 17:1-3. https://doi.org/10.1177/1559325819 838420

Alós E, Rodrigo MJ, Zacarias L (2016) Manipulation of carotenoid content in plants to improve human health. Subcell Biochem 79:311-343. https://doi.org/10.1007/978-3-319-39126-7_12

Apodaca SA, Tan W, Dominguez OE et al (2017) Physiological and biochemical effects of nanoparticulate copper, bulk copper, copper chloride, and kinetin in kidney bean (Phaseolus vulgaris) plants. Sci Total Environ 599-600:2085-2094. https:// doi.org/10.1016/j.scitotenv.2017.05.095 
Belz RG (2008) Stimulation versus inhibition-bioactivity of parthenin, a phytochemical from Parthenium hysterophorus $\mathrm{L}$. Dose-Response 6:80-96. https://doi.org/10.2203/dose-respo nse.07-007.Belz

Brito IP, Tropaldi L, Carbonari CA, Velini ED (2018) Hormetic effects of glyphosate on plants. Pest Manag Sci 74:1064-1070. https://doi.org/10.1002/ps.4523

Cai H, Liang J, Ning X, an, et al (2020) Algal toxicity induced by effluents from textile-dyeing wastewater treatment plants. J Environ Sci 91:199-208. https://doi.org/10.1016/j.jes.2020.01.004

Calabrese EJ, Agathokleous E, Kozumbo WJ et al (2019) Estimating the range of the maximum hormetic stimulatory response. Environ Res 170:337-343. https://doi.org/10.1016/j.envre s.2018.12.020

Calabrese EJ, Blain RB (2009) Hormesis and plant biology. Environ Pollut 157:42-48. https://doi.org/10.1016/j.envpol.2008.07.028

Carvalho MEA, Castro PRC, Azevedo RA (2020) Hormesis in plants under $\mathrm{Cd}$ exposure: from toxic to beneficial element? J Hazard Mater 384:121434. https://doi.org/10.1016/j.jhazm at.2019.121434

Cedergreen N, Olesen CF (2010) Can glyphosate stimulate photosynthesis? Pestic Biochem Physiol 96:140-148. https://doi. org/10.1016/j.pestbp.2009.11.002

Cedergreen N, Streibig JC, Kudsk P et al (2007) The occurrence of hormesis in plants and algae. Dose-Response 5:150-162. https ://doi.org/10.2203/dose-response.06-008.Cedergreen

Chae Y, Kim D, An YJ (2019) Effects of micro-sized polyethylene spheres on the marine microalga Dunaliella salina: Focusing on the algal cell to plastic particle size ratio. Aquat Toxicol 216:105296. https://doi.org/10.1016/j.aquatox.2019.105296

Chandra R, Kang H (2016) Mixed heavy metal stress on photosynthesis, transpiration rate, and chlorophyll content in poplar hybrids. Forest Sci Technol 12:55-61. https://doi.org/10.1080/21580 103.2015.1044024

Cooke J, Leishman MR (2016) Consistent alleviation of abiotic stress with silicon addition: a meta-analysis. Funct Ecol 30:1340-1357. https://doi.org/10.1111/1365-2435.12713

Dawood MFA, Azooz MM (2019) Concentration-dependent effects of tungstate on germination, growth, lignification-related enzymes, antioxidants, and reactive oxygen species in broccoli (Brassica oleracea var. italica L.). Environ Sci Pollut Res 26:36441-36457. https://doi.org/10.1007/s11356-019-06603-y

de Alkimin GD, Santos J, Soares AMVM, Nunes B (2020) Ecotoxicological effects of the azole antifungal agent clotrimazole on the macrophyte species Lemna minor and Lemna gibba. Comp Biochem Physiol C: Toxic Pharmacol 237:108835

de Carvalho LB, da Alves PL, CA, Bianco S, De Prado R, (2012) Physiological dose-response of coffee (Coffea arabica L.) plants to glyphosate depends on growth stage. Chil J Agric Res 72:182187. https://doi.org/10.4067/S0718-58392012000200003

Deng XY, Cheng J, Hu XL et al (2017) Biological effects of $\mathrm{TiO}_{2}$ and $\mathrm{CeO}_{2}$ nanoparticles on the growth, photosynthetic activity, and cellular components of a marine diatom Phaeodactylum tricornutum. Sci Total Environ 575:87-96. https://doi.org/10.1016/j. scitotenv.2016.10.003

Di Baccio D, Pietrini F, Bertolotto P et al (2017) Response of Lemna gibba L. to high and environmentally relevant concentrations of ibuprofen: Removal, metabolism and morpho-physiological traits for biomonitoring of emerging contaminants. Sci Total Environ 584-585:363-373. https://doi.org/10.1016/j.scito tenv.2016.12.191

Dong Y, Gao M, Song Z, Qiu W (2020) Microplastic particles increase arsenic toxicity to rice seedlings. Environ Pollut 259:113892. https://doi.org/10.1016/j.envpol.2019.113892

dos Santos MLS, de Almeida A-AF, da Silva NM, Oliveira BRM, Silva JVS, Junior JOS, Ahnert D, Baligar VC (2020) Mitigation of cadmium toxicity by zinc in juvenile cacao: Physiological, biochemical, molecular and micromorphological responses. Env Exp Bot 179:104201

Erofeeva EA (2014) Hormesis and paradoxical effects of wheat seedling (Triticum aestivum L.) parameters upon exposure to different pollutants in a wide range of doses. Dose Response 12:121-135. https://doi.org/10.2203/dose-response.13-017.Erofeeva

Erofeeva EA (2020) Estimating the frequency of hormesis and other non-monotonic responses in plants experiencing road traffic pollution in urban areas and experimental pollutant exposure. Environ Monit Assess 192:1-17. https://doi.org/10.1007/s1066 1-020-08418-8

Erofeeva EA, Yakimov BN (2020) Change of leaf trait asymmetry type in Tilia cordata Mill. and Betula pendula roth under air pollution. Symmetry 12:727. doi: https://doi.org/10.3390/sym12050727

Evans JR (2013) Improving photosynthesis. Plant Physiol 162:1780 1793. https://doi.org/10.1104/pp.113.219006

Fajer ED, Bazzaz FA (1992) Is carbon dioxide a 'good' greenhouse gas? Glob Environ Chang, Effects of increasing carbon dioxide on ecological systems. https://doi.org/10.1016/09593780(92)90047-b

Farzana S, Tam NFY (2018) A combined effect of polybrominated diphenyl ether and aquaculture effluent on growth and antioxidative response of mangrove plants. Chemosphere 201:483-491. https://doi.org/10.1016/j.chemosphere.2018.03.013

Garzon CD, Flores FJ (2013) Hormesis: biphasic dose-responses to fungicides in plant pathogens and their potential threat to agriculture. In: Fungicides - Showcases of Integrated Plant Disease Management from Around the World. InTech

Gelioli Salgado OG, Teodoro JC, Alvarenga JP et al (2019) Cerium alleviates drought-induced stress in Phaseolus vulgaris. J Rare Earths. https://doi.org/10.1016/j.jre.2019.07.014

Gohari G, Mohammadi A, Akbari A et al (2020) Titanium dioxide nanoparticles $\left(\mathrm{TiO}_{2} \mathrm{NPs}\right)$ promote growth and ameliorate salinity stress effects on essential oil profile and biochemical attributes of Dracocephalum moldavica. Sci Rep 10:1-14. https://doi. org/10.1038/s41598-020-57794-1

Gohari G, Safai F, Panahirad S et al (2020) Modified multiwall carbon nanotubes display either phytotoxic or growth promoting and stress protecting activity in Ocimum basilicum L. in a concentration-dependent manner. Chemosphere 249:126171. https://doi. org/10.1016/j.chemosphere.2020.126171

Guo X, Liu M, Zhong H et al (2020) Responses of the growth and physiological characteristics of Myriophyllum aquaticum to coexisting tetracyclines and copper in constructed wetland microcosms. Environ Pollut 261:114204. https://doi.org/10.1016/j. envpol.2020.114204

Gururani MA, Venkatesh J, Tran LSP (2015) Regulation of photosynthesis during abiotic stress-induced photoinhibition. Mol Plant 8:1304-1320

Hadacek F, Bachmann G, Engelmeier D, Chobot V (2010) Hormesis and a chemical Raison D'être for secondary plant metabolites. Dose Response 9:79-116. https://doi.org/10.2203/dose-respo nse.09-028.Hadacek

Havaux M (2014) Carotenoid oxidation products as stress signals in plants. Plant J 79:597-606

He X, You P, Sun Y (2020) Lanthanum and abscisic acid coregulate chlorophyll production of seedling in switchgrass. PLoS ONE 15:e0232750. https://doi.org/10.1371/journal.pone.0232750

Heath RL (1994) Possible mechanisms for the inhibition of photosynthesis by ozone. Photosynth Res 39:439-451

$\mathrm{Hu}$ H, Zhou Q, Li X et al (2019) Phytoremediation of anaerobically digested swine wastewater contaminated by oxytetracycline via Lemna aequinoctialis: Nutrient removal, growth characteristics and degradation pathways. Bioresour Technol 291:121853. https ://doi.org/10.1016/j.biortech.2019.121853 
Hussain S, Iqbal N, Brestic M et al (2019) Changes in morphology, chlorophyll fluorescence performance and Rubisco activity of soybean in response to foliar application of ionic titanium under normal light and shade environment. Sci Total Environ 658:626637. https://doi.org/10.1016/j.scitotenv.2018.12.182

Iavicoli I, Fontana L, Leso V, Calabrese EJ (2014) Hormetic doseresponses in nanotechnology studies. Sci Total Environ 487:361374. https://doi.org/10.1016/j.scitotenv.2014.04.023

Jalal A, Oliveira Junior JC, de, Ribeiro JS, et al (2021) Hormesis in plants: Physiological and biochemical responses. Ecotoxicol Environ Saf 207:111225

Jia L, Liu Z, Chen W et al (2015) Hormesis effects induced by cadmium on growth and photosynthetic performance in a hyperaccumulator, Lonicera japonica Thunb. J Plant Growth Regul 34:13-21. https://doi.org/10.1007/s00344-014-9433-1

Jiang Y, Liu Y, Zhang J (2020) Antibiotics induced alterations in cell density, photosynthesis, microcystin synthesis and proteomic expression of Microcystis aeruginosa during $\mathrm{CuSO}_{4}$ treatment. Aquat Toxicol 222:105473. https://doi.org/10.1016/j.aquat ox.2020.105473

Khan S, Zhou JL, Ren L, Mojiri A (2020) Effects of glyphosate on germination, photosynthesis and chloroplast morphology in tomato. Chemosphere 258:127350. https://doi.org/10.1016/j.chemospher e. 2020.127350

Kirschbaum MUF (2011) Does enhanced photosynthesis enhance growth? Lessons learned from $\mathrm{CO}_{2}$ enrichment studies. Plant Physiol 155:117-124. https://doi.org/10.1104/pp.110.166819

Kutty NN, Ghissing U, Kumar M et al (2020) Intense floral scent emission in Polianthes tuberosa L. (Tuberose) variants sprouted from $\gamma$-irradiated tubers. J Plant Growth Regul 39:112-121. https://doi. org/10.1007/s00344-019-09967-0

Lassalle G, Credoz A, Hédacq R et al (2019) Estimating persistent oil contamination in tropical region using vegetation indices and random forest regression. Ecotoxicol Environ Saf 184:109654. https://doi.org/10.1016/j.ecoenv.2019.109654

Li P, Feng Z, Catalayud V et al (2017) A meta-analysis on growth, physiological, and biochemical responses of woody species to ground-level ozone highlights the role of plant functional types. Plant Cell Environ 40:2369-2380. https://doi.org/10.1111/ pce. 13043

Li Y, Zhou C, Wang S et al (2019) Phytotoxicity and oxidative effects of typical quaternary ammonium compounds on wheat (Triticum aestivum L.) seedlings. Environ Sci Pollut Res 26:25985-25999. https://doi.org/10.1007/s11356-019-05822-7

Li J, Qiu Y, Zhao Q et al (2020a) Lead and copper-induced hormetic effect and toxicity mechanisms in lettuce (Lactuca sativa L.) grown in a contaminated soil. Sci Total Environ 741:140440. https://doi.org/10.1016/j.scitotenv.2020.140440

Li X, Yang C, Zeng G et al (2020b) Nutrient removal from swine wastewater with growing microalgae at various zinc concentrations. Algal Res 46:101804. https://doi.org/10.1016/j.algal .2020 .101804

Li Z, Li Q, Li R et al (2020c) Physiological response of cucumber seedlings to microplastics and cadmium. J Agro-Environment Sci 39:973-981

Li Z, Li Q, Li R et al (2020d) Physiological responses of lettuce (Lactuca sativa L.) to microplastic pollution. Environ Sci Pollut Res 27:30306-30314. https://doi.org/10.1007/s11356-020-09349-0

Li Z, Song Z, Yan Z et al (2018) Silicon enhancement of estimated plant biomass carbon accumulation under abiotic and biotic stresses. A meta-analysis Agron Sustain Dev 38:1-19

Lian J, Wu J, Xiong H et al (2020) Impact of polystyrene nanoplastics (PSNPs) on seed germination and seedling growth of wheat (Triticum aestivum L.). J Hazard Mater 385:121620. https://doi. org/10.1016/j.jhazmat.2019.121620
Liu N, Zhong G, Zhou J et al (2019) Separate and combined effects of glyphosate and copper on growth and antioxidative enzymes in Salvinia natans (L.) All. Sci Total Environ 655:1448-1456. https ://doi.org/10.1016/j.scitotenv.2018.11.213

Liu Y, Pang Y, Yang L et al (2020) Responses of Hydrocharis dubia (B1.) Backer and Trapa bispinosa Roxb to tetracycline exposure. Ecotoxicol Environ Saf 202:110890. https://doi.org/10.1016/j. ecoenv. 2020.110890

Liu Y, Yang Q, Zhu M et al (2020) Endocytosis in Microcystis aeruginosa accelerates the synthesis of microcystins in the presence of lanthanum(III). Harmful Algae 93:101791. https://doi. org/10.1016/j.hal.2020.101791

Macias-Bobadilla I, Vargas-Hernandez M, Guevara-Gonzalez RG et al (2020) Hormetic and xenohormetic potential in the phytobiome of the center of origin. Genet Resour Crop Evol 67:1331-1344. https://doi.org/10.1007/s10722-020-00912-9

Małkowski E, Sitko K, Szopiński M et al (2020) Hormesis in plants: The role of oxidative stress, auxins and photosynthesis in corn treated with $\mathrm{Cd}$ or Pb. Int J Mol Sci 21:2099. https://doi. org/10.3390/ijms21062099

Mendonça AM, das C, Lira JMS, Vilela AL de O, et al (2019) High aluminum concentration and initial establishment of Handroanthus impetiginosus: Clues about an $\mathrm{Al}$ non-resistant species in Brazilian Cerrado. J For Res (In Press). https://doi.org/10.1007/ s11676-019-01033-5

Meseldžija M, Lazić S, Dudić M et al (2020) Is there a possibility to involve the hormesis effect on the soybean with glyphosate sub-lethal amounts used to control weed species Amaranthus retroflexus L? Agronomy 10:850. https://doi.org/10.3390/agron omy 10060850

Mo F, Li H, Li Y et al (2020) Toxicity of $\mathrm{Ag}^{+}$on microstructure, biochemical activities and genic material of Trifolium pratense L. seedlings with special reference to phytoremediation. Ecotoxicol Environ Saf 195:110499. https://doi.org/10.1016/j. ecoenv.2020.110499

Morkunas I, Woźniak A, Mai V et al (2018) The role of heavy metals in plant response to biotic stress. Molecules 23:2320. https:// doi.org/10.3390/molecules23092320

Mostofa MG, Rahman A, Ansary MMU et al (2015) Hydrogen sulfide modulates cadmium-induced physiological and biochemical responses to alleviate cadmium toxicity in rice. Sci Rep 5:14078. https://doi.org/10.1038/srep14078

Nascentes RF, Carbonari CA, Simões PS et al (2018) Low doses of glyphosate enhance growth, $\mathrm{CO}_{2}$ assimilation, stomatal conductance and transpiration in sugarcane and eucalyptus. Pest Manag Sci 74:1197-1205. https://doi.org/10.1002/ps.4606

Nisar N, Li L, Lu S et al (2015) Carotenoid metabolism in plants. Mol Plant 8:68-82. https://doi.org/10.1016/j.molp.2014.12.007

Pignattelli S, Broccoli A, Renzi M (2020) Physiological responses of garden cress (L. sativum) to different types of microplastics. Sci Total Environ 727:138609. https://doi.org/10.1016/j.scito tenv.2020.138609

Pinnola A, Griffiths H (2019) The rise and fall of Light-Harvesting Complex Stress-Related proteins as photoprotection agents during evolution. J Exp Bot 70:5527-5535. https://doi. org/10.1093/jxb/erz317

Poschenrieder C, Cabot C, Martos S et al (2013) Do toxic ions induce hormesis in plants? Plant Sci 212:15-25. https://doi. org/10.1016/j.plantsci.2013.07.012

Rioboo C, González O, Herrero C, Cid A (2002) Physiological response of freshwater microalga (Chlorella vulgaris) to triazine and phenylurea herbicides. Aquat Toxicol 59:225-235. https://doi.org/10.1016/S0166-445x(01)00255-7

Sand-Jensen K (1997) Broad-scale comparison of photosynthesis in terrestrial and aquatic plant communities. Oikos 80:203. https ://doi.org/10.2307/3546536 
Seth CS, Kumar Chaturvedi P, Misra V (2008) The role of phytochelatins and antioxidants in tolerance to $\mathrm{Cd}$ accumulation in Brassica juncea L. Ecotoxicol Environ Saf 71:76-85. https:// doi.org/10.1016/j.ecoenv.2007.10.030

Shahid M, Niazi NK, Rinklebe J et al (2020) Trace elementsinduced phytohormesis: A critical review and mechanistic interpretation. Crit Rev Environ Sci Technol. https://doi. org/10.1080/10643389.2019.1689061

Sharma PK, Raghubanshi AS, Shah K (2020) Examining the uptake and bioaccumulation of molybdenum nanoparticles and their effect on antioxidant activities in growing rice seedlings. Environ Sci Pollut Res. https://doi.org/10.1007/s11356-020-11511-7

Simkin AJ, López-Calcagno PE, Raines CA (2019) Feeding the world: Improving photosynthetic efficiency for sustainable crop production. J Exp Bot 70:1119-1140

Sinclair TR, Rufty TW, Lewis RS (2019) Increasing photosynthesis: Unlikely solution for world food problem. Trends Plant Sci 24:1032-1039. https://doi.org/10.1016/j.tplants.2019.07.008

Soliman M, Alhaithloul HA, Hakeem KR et al (2019) Exogenous nitric oxide mitigates nickel-induced oxidative damage in eggplant by upregulating antioxidants, osmolyte metabolism, and glyoxalase systems. Plants 8:562. https://doi.org/10.3390/plant s8120562

Song C, Liu Z, Wang C et al (2020) Different interaction performance between microplastics and microalgae: The bio-elimination potential of Chlorella sp. L38 and Phaeodactylum tricornutum MASCC-0025. Sci Total Environ 723:138146. https://doi. org/10.1016/j.scitotenv.2020.138146

South PF, Cavanagh AP, Liu HW, Ort DR (2019) Synthetic glycolate metabolism pathways stimulate crop growth and productivity in the field. Science 363:eaat9077. doi: https://doi.org/10.1126/ science.aat 9077

Su Y, Zhang K, Zhou Z et al (2020) Microplastic exposure represses the growth of endosymbiotic dinoflagellate Cladocopium goreaui in culture through affecting its apoptosis and metabolism. Chemosphere 244:125485. https://doi.org/10.1016/j.chemospher e.2019.125485

Sugai T, Kam D-G, Agathokleous E et al (2018) Growth and photosynthetic response of two larches exposed to $\mathrm{O}_{3}$ mixing ratios ranging from preindustrial to near future. Photosynthetica 56:901910. https://doi.org/10.1007/s11099-017-0747-7

Tang J, Ni X, Zhou Z et al (2018) Acute microplastic exposure raises stress response and suppresses detoxification and immune capacities in the scleractinian coral Pocillopora damicornis. Environ Pollut 243:66-74. https://doi.org/10.1016/j.envpol.2018.08.045

Tang YT, Qiu RL, Zeng XW et al (2009) Lead, zinc, cadmium hyperaccumulation and growth stimulation in Arabis paniculata Franch. Environ Exp Bot 66:126-134. https://doi.org/10.1016/j.envex pbot.2008.12.016

Tombuloglu H, Slimani Y, Tombuloglu G et al (2019) Tracking of $\mathrm{NiFe} 2 \mathrm{O} 4$ nanoparticles in barley (Hordeum vulgare $\mathrm{L}$.) and their impact on plant growth, biomass, pigmentation, catalase activity, and mineral uptake. Environ Nanotech Monit Manag 11:100223. https://doi.org/10.1016/j.enmm.2019.100223

Tong M, Li X, Luo Q et al (2020) Effects of humic acids on biotoxicity of tetracycline to microalgae Coelastrella sp. Algal Res 50:101962. https://doi.org/10.1016/j.algal.2020.101962
Trejo-Téllez LI, García-Jiménez A, Escobar-Sepúlveda HF et al (2020) Silicon induces hormetic dose-response effects on growth and concentrations of chlorophylls, amino acids and sugars in pepper plants during the early developmental stage. PeerJ 8:e9224. https ://doi.org/10.7717/peerj.9224

Wang C, Zhang H, Ruan L et al (2016) Bioaccumulation of ${ }^{13} \mathrm{C}$-fullerenol nanomaterials in wheat. Environ Sci Nano 3:799-805. https ://doi.org/10.1039/c5en00276a

Wong PK, Chang L (1988) The effects of 2,4-D herbicide and organophosphorus insecticides on growth, photosynthesis, and chlorophyll a synthesis of Chlamydomonas reinhardtii $(\mathrm{mt}+)$. Environ Pollut 55:179-189

Wu M, Luo Q, Zhao Y et al (2018) Physiological and biochemical mechanisms preventing Cd toxicity in the new hyperaccumulator Abelmoschus manihot. J Plant Growth Regul 37:709-718. https ://doi.org/10.1007/s00344-017-9765-8

Xu J, Zhang J, Lv Y et al (2020) Effect of soil mercury pollution on ginger (Zingiber officinale Roscoe): Growth, product quality, health risks and silicon mitigation. Ecotoxicol Environ Saf 195:110472. https://doi.org/10.1016/j.ecoenv.2020.110472

Xue R, Fu L, Dong S et al (2020) Promoting Chlorella photosynthesis and bioresource production using directionally prepared carbon dots with tunable emission. J Colloid Interface Sci 569:195-203. https://doi.org/10.1016/j.jcis.2020.02.080

Yang Y, Zhang L, Huang X et al (2020) Response of photosynthesis to different concentrations of heavy metals in Davidia involucrata. PLoS ONE 15:e0228563. https://doi.org/10.1371/journ al.pone. 0228563

Zaltauskaite J, Kaciene G (2020) Lemna minor recovery potential after short-term exposure to sulfonylurea herbicide. Acta Physiol Plant 42:1-9. https://doi.org/10.1007/s11738-020-3022-7

Zhang F, Zhao D, Chi J (2020) Impact of different environmental particles on degradation of dibutyl phthalate in coastal sediments with and without Cylindrotheca closterium. Environ Pollut 261:114228. https://doi.org/10.1016/j.envpol.2020.114228

Zhang H, Tang X, Shang J et al (2018) The effect of naphthenic acids on physiological characteristics of the microalgae Phaeodactylum tricornutum and Platymonas helgolandica var. tsingtaoensis. Environ Pollut 240:549-556. https://doi.org/10.1016/j.envpo 1.2018.04.126

Zhao T, Tan L, Huang W, Wang J (2019) The interactions between micro polyvinyl chloride (mPVC) and marine dinoflagellate Karenia mikimotoi: The inhibition of growth, chlorophyll and photosynthetic efficiency. Environ Pollut 247:883-889. https:// doi.org/10.1016/j.envpol.2019.01.114

Zhou Q, Li F, Ge F et al (2016) Nutrient removal by Chlorella vulgaris F1068 under cetyltrimethyl ammonium bromide induced hormesis. Environ Sci Pollut Res 23:19450-19460. https://doi. org/10.1007/s11356-016-6999-0

Zhou Q, Lin Y, Li X et al (2018) Effect of zinc ions on nutrient removal and growth of Lemna aequinoctialis from anaerobically digested swine wastewater. Bioresour Technol 249:457-463. https://doi. org/10.1016/j.biortech.2017.10.044

Publisher's Note Springer Nature remains neutral with regard to jurisdictional claims in published maps and institutional affiliations. 